American Journal of Applied Sciences 6 (11): 1960-1968, 2009

ISSN 1546-9239

(C) 2009 Science Publications

\title{
Modeling of Biological Processes by Using Membrane Computing Formalism
}

\author{
Ravie Chandren Muniyandi and Abdullah Mohd. Zin \\ Faculty of Technology and Information Science, National University of Malaysia, \\ 43600 Bangi, Selangor, Malaysia
}

\begin{abstract}
Problem statement: Membrane computing has structural resemblance with the cell structure. This characteristic provides the versatility in the modeling of biological processes. Approach: This study was carried to discuss the membrane computing formalism in modeling biological processes by analyzing two examples: Photosynthesis in chloroplast and Sodium-Potassium exchange pump. Results: The modeling of these two examples showed membrane computing formalism has the capability to capture the fundamental features and elements of biological processes. Conclusion: There are flexibilities and advantages in modeling biological processes with membrane computing but its formalism need further expansion to accommodate complex biological processes.
\end{abstract}

Key words: Membrane computing formalism, modeling biological processes

\section{INTRODUCTION}

The growing interest in analyzing various biological or natural processes has increased the need for an appropriate computing model to represent biological processes in a formal and feasible way.

The conventional modeling approaches are based on differential equations and have shown disadvantages when dealing with stochastic and nondeterministic processes. Recently, there has been growing interest in using the framework of membrane computing, a theoretical paradigm abstracting from the structure and functionality of the living cell, as models and simulators of cellular phenomena, and hence producing formal specifications defined in a language that is close to molecular biology and returning meaningful and easy to be interpreted information to biologists. In this respect there have been investigations into modeling various aspects of molecular and cellular biology. Examples include models of photosynthesis in chloroplast dealing with light reaction and photoinhibition $^{[1]}$, specifications of leukocyte selective recruitment in immune system ${ }^{[2]}$, descriptions of mechanosensitive channels behavior in E. coli ${ }^{[3]}$, definitions of Sodium-Potassium exchange pump in animal cells ${ }^{[4]}$ and comprehensive approaches on Quorum Sensing aspects in Vibrio Fischeri ${ }^{[5]}$.

This study is focusing on two biological processes. These processes are analyzed and discussed to show the use of membrane computing to define models of specific cellular systems. The chosen examples are
Photosynthesis in chloroplast dealing with light reaction and photoinhibition and Sodium-Potassium exchange pump in animal cells. This study will describe the biological process involved in each case, type of objects, rules, and how these elements are represented using membrane computing formalism as well as ways of simulating the system.

Membrane computing formalism: The followings are the fundamental aspects of membrane computing formalism ${ }^{[6-8]}$ :

Membrane system: The membrane system II is represented as $\Pi=\left(\mathrm{V}, \mu, \omega_{1}, \omega_{2}, \ldots, \omega_{n}, R_{1}, R_{2}, \ldots, R_{n}\right)$. The system $\Pi$ contains objects $V$, structure of the system $\mu$, multisets $\omega_{1}, \omega_{2}, \ldots, \omega_{n}$ and rules $R_{1}, R_{2}$, $, \ldots, \mathrm{R}_{\mathrm{n}} .1,2, \ldots, \mathrm{n}$ are the labels of the compartments in the system. There are $\mathrm{n}$ compartments, in which each of them consists of multisets and rules. In this case, compartment with label 1 consists of multiset $\omega_{1}$ and rule $\mathrm{R}_{1}$; compartment with label 2 consists of multiset $\omega_{2}$ and rule $R_{2}$ and so forth for the other compartments.

Membrane structure: The membrane structure $\mu$ is represented by a string of matching parentheses. It determines the possible bi-directional links between the adjacent compartments. For instance, $\mu=\left[[]_{2}\left[[]_{4}\right]_{3}\right]_{1}$ has four compartments, in which, compartment 1 is linked to compartment 2 and 3; compartment 2 is linked to compartment 1 and 3; compartment 3 is linked to compartment 1, 2 and 4; and compartment 4 is linked

Corresponding Author: Ravie Chandren Muniyandi, Faculty of Technology and Information Science, National University of Malaysia, 43600 Bangi, Selangor, Malaysia 
only to compartment 3 . Links between compartments are used to establish the communication between compartments. For example, if compartment 1 need to communicate with compartment 4 , it has to go through the established links in the membrane structure since there is no direct link between compartment 1 and compartment 4 . It is only possible for compartment 3 to have direct link to compartment 4 . In this case, at first compartment 1 has to communicate with compartment 3 , before the message is passed to compartment 4 .

Objects: $X_{1}, X_{2}, \ldots, X_{i}$, are finite alphabet of symbols $\Pi$ called objects. In membrane system, objects are represented as $\mathrm{V}=\left\{\mathrm{X}_{1}, \mathrm{X}_{2}, \ldots, \mathrm{X}_{\mathrm{i}}\right\}$. This means that there are $\mathrm{i}$ different objects in the membrane system. If objects $X_{1}$ and $X_{2}$ are able to form a complex or bind to each other, then the new object produced could be represented as $\mathrm{X}_{1}-\mathrm{X}_{2}$.

Multiset: Objects could be multiplied in numbers to determine its recurrence and this is called multiplicity. An element of a multiset has a multiplicity, which could be either a natural number or real number. The multiset is characterized as $\omega_{\mathrm{j}}=\left\{\mathrm{m}_{1} \mathrm{X}_{1}, \mathrm{~m}_{2} \mathrm{X}_{2}, \ldots, \mathrm{m}_{\mathrm{i}} \mathrm{X}_{\mathrm{i}}\right\}$ in which, $\mathrm{m}_{1}, \mathrm{~m}_{2}, \ldots, \mathrm{m}_{\mathrm{i}}$ are multiplicities of objects $\mathrm{X}_{1}$, $\mathrm{X}_{2}, \ldots, \mathrm{X}_{\mathrm{i}}$ respectively. If there is more than one type of object in the multiset, comma is used as separator between objects to identify each of them as a unique entity in a compartment. For instance, $\left[\mathrm{m}_{1} \mathrm{X}_{1}, \mathrm{~m}_{2} \mathrm{X}_{2}\right]_{\mathrm{a}}$ refers to $\mathrm{m}_{1}$ units of $\mathrm{X}_{1}$ and $\mathrm{m}_{2}$ units of $\mathrm{X}_{2}$ in compartment a.

Rules: The evolution rule is represented in the format:

$$
\mathrm{R}_{\mathrm{j}} \mathrm{C}>\mathrm{m}[\mathrm{v}]_{\mathrm{j}} \stackrel{\mathrm{k}}{\longrightarrow} \mathrm{u}^{\prime}\left[\mathrm{v}^{\prime}\right]_{\mathrm{j}}
$$

$R_{j} \quad=$ The label of the rule in compartment $\mathrm{j}$

$\mathrm{u}, \mathrm{v}, \mathrm{u}^{\prime}, \mathrm{v}^{\prime}=$ Multisets

$\mathrm{k}=$ Reactivity rate or constant assigned to the rule

C = Condition to determine either the rule can be executed or not

$\mathrm{C}$ and $\mathrm{k}$ are optional in the rule. $\mathrm{A}$ rule $\mathrm{R}_{\mathrm{j}}$ is interpreted as follow: If the condition $\mathrm{C}$ is true, then the rule is implemented based on value of $\mathrm{k}$ with multiset $\mathrm{u}$ outside membrane $\mathrm{j}$ and multiset $\mathrm{v}$ inside membrane $\mathrm{j}$ react together to produce multiset $u^{\prime}$ outside $\mathrm{j}$ and multiset $\mathrm{v}^{\prime}$ inside $\mathrm{j}$. If there is more than one rule in compartment $\mathrm{j}$, the rules are labeled as $n R_{j} 1, R_{j}$
$2, \ldots, \mathrm{R}_{\mathrm{j}} \mathrm{n}$ to refer to each of the $\mathrm{n}$ rules. The two common evolution rules in biological processes are:

- Transformation rule: It is a rewriting rule that occur between objects inside a compartment. For example the rule $[\mathrm{X}, \mathrm{X}]_{\mathrm{j}} \rightarrow[\mathrm{X}, \mathrm{Y}]$, [means that, when there are 2 objects of $X$ available in compartment $\mathrm{j}$, they can interact each other to generate an object $\mathrm{X}$ and an object $\mathrm{Y}$

- Communication rule: It is a transportation of object from a compartment to another compartment. It can be either an object in a compartment moving out or an object moving into a compartment. $\mathrm{Y}[\mathrm{X}]_{\mathrm{j}} \rightarrow[\mathrm{X}, \mathrm{Y}]_{\mathrm{j}}$ : In this communication rule, object $\mathrm{Y}$ which is outside compartment $\mathrm{j}$ is moving into that compartment. $[\mathrm{Y}, \mathrm{X}]_{\mathrm{j}} \rightarrow \mathrm{Y}[\mathrm{X}]_{\mathrm{j}}$ : In this communication rule, object $\mathrm{Y}$, which is inside compartment $\mathrm{j}$ is moving out of the compartment

Photosynthesis in chloroplast: Photosynthesis ${ }^{[1,6]}$ of higher plants occurs in the chloroplast, where many membrane-surrounded structures called thylakoids can be found. The region enclosed by the thylakoid membrane is called the lumen. The space between the chloroplast envelope and thylakoids is named the stroma. Photosynthesis reactions are classified into light reactions and dark reactions.

Light reactions separate water into $\mathrm{O}_{2}$ and $\mathrm{H}^{+}$, reduce NADP to NADPH and synthesize ATP. In thylakoids membranes light is absorbed by the antenna pigments of Photo Systems I (PSI) and Photosy Stems II (PSII). PSI and PSII are excited by light at longer wavelength and shorter wavelength, respectively. PSI reduces NADP in stroma.

PSII splits water in lumen and transports $\mathrm{H}$ from stroma to lumen. The light reactions are summarized as follow, where $\mathrm{v}$ represents photon, PS represents photosystem and, L and S represents lumen and stroma:

$$
\begin{aligned}
& 2 \mathrm{H}_{2} \mathrm{O}(\mathrm{L}) \stackrel{\mathrm{PS}, \mathrm{v}}{\longrightarrow} \mathrm{O}_{2}(\mathrm{~L})+4 \mathrm{H}^{+}(\mathrm{L}) \\
& 2 \mathrm{NADP}(\mathrm{S})+2 \mathrm{H}^{+}(\mathrm{S}) \stackrel{\mathrm{PS}, \mathrm{v}}{\longrightarrow} 2 \mathrm{NADPH}(\mathrm{S}) \\
& 4 \mathrm{H}^{+}(\mathrm{S}) \stackrel{\mathrm{PS}, \mathrm{v}}{\longrightarrow} 4 \mathrm{H}^{+}(\mathrm{L})
\end{aligned}
$$

Thus, these reactions are linked to each other and as a consequence of these reactions, the concentration of $\mathrm{H}^{+}$in the lumen increases. This will also increase the $\mathrm{pH}$ level. As the result, ATP is synthesized using the chemical potential of $\mathrm{H}^{+}$in the thylakoid membrane. The reaction is as follow, where $\mathrm{P}$ stands for phosphoric acid and $n$ is the number of $\mathrm{H}^{+}$which are required for ATP synthesis: 
$\mathrm{ADP}(\mathrm{S})+\mathrm{P}(\mathrm{S})+\mathrm{nH}^{+}(\mathrm{L}) \rightarrow \mathrm{ATP}+\mathrm{nH}^{+}(\mathrm{S})$

Dark reactions occur in stroma to make starch from $\mathrm{CO}_{2}$ and $\mathrm{H}_{2} \mathrm{O}$ using the reduction power of NADPH and chemical energy of ATP. The reaction is:

$\mathrm{CO}_{2}+4 \mathrm{NADPH} \rightarrow \mathrm{CH}_{2} \mathrm{O}+4 \mathrm{NADP}+\mathrm{HO}$

Meanwhile, photo-inhibition is a mechanism to repress light reaction in high luminosity. One of the photoinhibition mechanisms consists of reactions, which occurs when there is no NADP in the stroma and the $\mathrm{pH}$ in the lumen is less than 5:

$2 \mathrm{H}_{2} \mathrm{O}(\mathrm{L}) \stackrel{\mathrm{PS}, \mathrm{v}}{\longrightarrow} \mathrm{O}_{2}(\mathrm{~L})+4 \mathrm{H}^{+}(\mathrm{L})$

$\mathrm{O}_{2}(\mathrm{~S})+4 \mathrm{H}^{+}(\mathrm{S}) \stackrel{\mathrm{PS}, \mathrm{v}}{\longrightarrow} 2 \mathrm{H}_{2} \mathrm{O}(\mathrm{S})$

$4 \mathrm{H}^{+}(\mathrm{L})+\mathrm{O}_{2}(\mathrm{~L}) \rightarrow 2 \mathrm{H}_{2} \mathrm{O}(\mathrm{L})$

$2 \mathrm{NADPH}(\mathrm{S})+2 \mathrm{H}^{+}(\mathrm{S})+\mathrm{O}_{2}(\mathrm{~S}) \rightarrow \mathrm{M}$

where, $\mathrm{M}=2 \mathrm{H}_{2} \mathrm{O}(\mathrm{S})+2 \mathrm{NADP}(\mathrm{S})$.

Sodium-potassium exchange pump: The NaKpump (sodium-potassium exchange pump) ${ }^{[4,9]}$ is a primary active transport system driven by a cell membrane ATPase carrying sodium ions outside and potassium ions inside the cell. It establishes and maintains the appropriate internal concentrations of sodium and potassium ions in cells, and this important physiological process present in all animal cells. The NaKpump has two conformations, called $E_{1}$ and $E_{2}$ which correspond to the mutually exclusive states in which the pump exposes ion binding sites alternatively on the intracellular and extracellular sides of the membrane. Ion transport is mediated by transitions between these conformations. During the translocation across cell membrane, there exist conformations in which the transported ions are occluded (trapped within the protein) before being released to the other side, and thus unable to be in contact with the surrounding media.

The processes ${ }^{[4]}$ are as follow:

(a) At this state the pump is in the conformation $\mathrm{E}_{1}$ and it is associated with ATP ( $\mathrm{E}_{1}$-ATP). Its binding sites are empty and open to the intracellular space. In this situation, the affinity is high for $\mathrm{Na}$ ions and low for $\mathrm{K}$ ions

(b) Consequently, three $\mathrm{Na}$ ions bind to the intracellular sites. The binding of $\mathrm{Na}$ ions catalyzes a phosphorylation of the pump by the previously bound ATP in which certain amount of phosphate in ATP is transferred to change the pump structure

(c) The new conformation of the pump is described as $\mathrm{E}_{1}^{\mathrm{P}}$. During this process, $\mathrm{Na}$ ions are occluded

(d) Thereafter the pump undergoes a conformational change to the $\mathrm{E}_{2}^{\mathrm{P}}$ state and loses its affinity for $\mathrm{Na}$ ions. The $\mathrm{Na}$ ions are subsequently released; first one $\mathrm{Na}$ ion is released during the conformational change from $\mathrm{E}_{1}{ }^{\mathrm{P}}-\mathrm{E}_{2}{ }^{\mathrm{P}}$ when the binding sites are oriented toward the extracellular side

(e) The pump is in the $\mathrm{E}_{2}^{\mathrm{P}}$ state and the affinity for $\mathrm{Na}$ ions is very low; the two remaining $\mathrm{Na}$ ions are released into the extracellular medium. The binding sites now have a high affinity for $\mathrm{K}$ ions

(f) Two external $\mathrm{K}$ ions can bind at this state

(g) The binding of $\mathrm{K}$ ions at the outer surface induces the dephosphorylation of the $\mathrm{E}_{2}^{\mathrm{P}}$ conformation, which turns to $E_{2}$. The release of the phosphate into the intracellular medium is accompanied by the occlusion of the $\mathrm{K}$ ions

(h) De-occlusion of $\mathrm{K}$ ions to the intracellular space is then catalyzed by ATP. The pump returns to the conformation $\mathrm{E}_{1}$ which has high affinity for $\mathrm{Na}$ ions and presents the binding with ATP. The affinity for $\mathrm{K}$ ions reduces and they are released into the intracellular medium. The pump is now ready to initiate a new cycle from the active conformation $\mathrm{E}_{1}$-ATP by going into state (a)

\section{MATERIALS AND METHODS}

Reactions and parameters: The information about biological reactions and the parameters required for the reactions of the two examples of biological processes are extracted from the related journal papers ${ }^{[1,3]}$. This reactions and parameters are used in modeling biological processes using membrane computing formalism.

Modeling: The examples of biological processes are modeled based on membrane computing formalism outlined in the Introduction section. Here how the biological processes could be modeled using membrane computing formalism are presented and discussed.

\section{RESULTS}

Modeling Photosynthesis in chloroplast: The system that models photosynthesis reactions and photoinhibition works in a fully parallel mode. Subsequently the behavior of this system will be defined by the following formal membrane computing, where S, T and L represent compartments of stroma, thylakoid and lumen, respectively: 
Photo $=\left(\mathrm{V}, \mu, \omega_{\mathrm{S}}, \omega_{\mathrm{R}}, \omega_{\mathrm{L}}, \mathrm{R}_{\mathrm{S}}, \mathrm{R}_{\mathrm{T}}, \mathrm{R}_{\mathrm{L}}\right)$

In the above reactions (1-9), the molecules $\mathrm{H}_{2} \mathrm{O}$, $\mathrm{CO}_{2}$, ADP, ATP and $\mathrm{O}_{2}$ can be considered constant because they are supplied from air or to stabilize other mechanisms. Therefore, the alphabet $\mathrm{V}$ contains six objects that are used to determine the behavior of the system. PSI and PSII are pigments of photosystems that are excited by light at longer and shorter wavelength. PSII is categorized into PSIIh and PSIIl, which have high and low activity. The concentration of $\mathrm{H}$ determines the PH level. NADP and NADPH establish the activity of photoinhibition. So, formally, the objects are:

$\mathrm{V}=\left\{\mathrm{H}^{+}, \mathrm{NADP}, \mathrm{NADPH}, \mathrm{PSI}, \mathrm{PSIIh}, \mathrm{PSIII}\right\}$

The tylakoid membrane triggers specific reactions and consequently it would be appropriate to assume that it acts as a separate compartment with its own rules and objects inside it. Therefore, the system is represented as a three membrane structure in the hierarchical form. The membrane structure is thus described as:

$\left.\mu\left[[]_{\mathrm{L}}\right]_{\mathrm{T}}\right]_{\mathrm{S}}$

The multisets $\omega_{\mathrm{S}}, \omega_{\mathrm{T}}, \omega_{\mathrm{L}}$ represent the initial contents of the stroma, thylakoid and lumen, respectively. The initial multisets of Photo with real number multiplicities of $\mathrm{m}_{1}, \mathrm{~m}_{2}, \ldots \mathrm{m}_{5}$ are:

$\omega_{\mathrm{S}}=\left\{\mathrm{m}_{1} \mathrm{H}^{+}, \mathrm{m}_{2} \mathrm{NADP}\right\}$

$\omega_{\mathrm{T}}=\left\{\mathrm{m}_{3} \mathrm{PSI}, \mathrm{m}_{4} \mathrm{PSIIh}\right\}$

$\omega_{\mathrm{L}}=\left\{\mathrm{m}_{5} \mathrm{H}^{+}\right\}$

Reactivity rates are used together with specific constants to compute multiplicities of objects occurring in various rules. The constants are $\mathrm{C}_{\mathrm{PS}}, \mathrm{C}_{\mathrm{L}}, \mathrm{C}_{\mathrm{ATP}}$ and correspond to the recovering of PSIIh, the maximum water splitting in lumen, and the maximum ATP synthesis in the tylakoid membrane. Probabilities, strength of photon, thresholds and amount of objects are used to compute reactivity rates. Reacting probabilities of photosynthesis are represented as $\mathrm{p}_{1}$, $\mathrm{p}_{1}^{\prime}, \mathrm{p}_{8}$ and $\mathrm{p}_{\mathrm{PS}}$.

Probabilities $\mathrm{p}_{1}$ and $\mathrm{p}_{1}{ }_{1}$ are used to determine to distinguish the dependency of certain reaction to photosystems. Probability $\mathrm{p}_{8}$ is used to regulate the difference in the numbers of $\mathrm{H}^{+}$in lumen and stroma. Probability $\mathrm{p}_{\mathrm{PS}}$ is to determine PSII decreasing reaction. The photons $\mathrm{v}$ and $\mathrm{v}_{0}$ represent specific and normal strength of light. $\theta_{\mathrm{ATP}}, \theta_{\mathrm{NADP}}$ and $\theta_{\mathrm{H}}$ are thresholds that represent the amount of molecule ATP, NADP and $\mathrm{H}^{+}$. Thresholds are used to determine the condition to pick certain reactivity rate. The amount of object $\mathrm{X}$ incompartment a is represented as $\mathrm{A}_{\mathrm{a}}(\mathrm{X})$.

The Reactivity rates $r_{1}, r_{2}, r_{3}, r_{4}, r_{5}, r_{6}, r_{7}, r_{8}, r_{9}$ are for reaction (1-9), respectively. $r_{P S}$ is reactivity rate in photosystem. These reactivity rates are computed using specific formulas ${ }^{[6]}$ based on the character of those reactions in photosynthesis, for instance:

$\mathrm{r}_{\mathrm{ps}}=1-\exp \left(-\mathrm{p}_{\mathrm{PS}} \mathrm{v} \mathrm{A}_{\mathrm{T}}(\mathrm{PSIIh})\right)$

The evolution rules are written in the format:

$\mathrm{R}_{\mathrm{a}}: \mathrm{u}[\mathrm{v}]_{\mathrm{a}} \stackrel{\mathrm{r}_{1}, \ldots, \mathrm{r}_{\mathrm{g}}, \mathrm{r}_{\mathrm{PS}} \mathrm{C}_{\mathrm{pS}}, \mathrm{C}_{\mathrm{L}}, \mathrm{C}_{\mathrm{ATP}}}{\longrightarrow} \mathrm{u}^{\prime}\left[\mathrm{v}^{\prime}\right]_{\mathrm{a}}$

where, $r_{1}, r_{2}, r_{3}, r_{4}, r_{5}, r_{6}, r_{7}, r_{8}, r_{9}, r_{P S}$ are reactivity rates and $\mathrm{C}_{\mathrm{PS}}, \mathrm{C}_{\mathrm{L}}, \mathrm{C}_{\mathrm{ATP}}$ are constants.

In order to compute the multiplicities, the rule could use both reactivity rates and constants, or either one of them. There could also be one or more reactivity rates and constants in the rule. The multiplicities $\mathrm{m}_{1}$, $\mathrm{m}_{2}, \ldots \mathrm{m}_{11}$ are computed at each step of simulation by using the reactivity rates, the constants and the concentration of objects in each region. The rules and formulas to generate multiplicities in Photo are constructed by considering the reactants and products of reactions in the photosynthesis given above. These rules and multiplicities are specified as follows:

Rule $R_{S} 1$ is formulated from reaction (2). It transforms one NADP into $m_{1}$ NADP and $m_{2}$ NADPH:

$\mathrm{R}_{\mathrm{S}} 1:[\mathrm{NADP}]_{\mathrm{S}} \stackrel{\mathrm{r}_{2}}{\longrightarrow}\left[\mathrm{m}_{1} \mathrm{NADP}, \mathrm{m}_{2} \mathrm{NADPH}\right]_{\mathrm{S}}$

Where:

$\mathrm{m}_{1}=\left(1-2 \mathrm{r}_{2}\right) \mathrm{A}_{\mathrm{s}}(\mathrm{NADP})$

$\mathrm{m}_{2}=2 \mathrm{r}_{2} \mathrm{~A}_{\mathrm{s}}$ (NADP)

Rule $\mathrm{R}_{\mathrm{S}} 2$ is formulated from reaction (5) and (9). It transforms one NADPH into $m_{3} \mathrm{NADPH}$ and $\mathrm{m}_{4} \mathrm{NADP}$.

Rules $R_{S} 1$ and $R_{S} 2$ determine the activity of photoinhibition:

$\mathrm{R}_{\mathrm{s}} 2:[\mathrm{NADPH}]_{\mathrm{S}} \stackrel{\mathrm{r}_{5}, \mathrm{r}_{9}}{\longrightarrow}\left[\mathrm{m}_{3} \mathrm{NADPH}, \mathrm{m}_{4} \mathrm{NADP}\right]_{\mathrm{S}}$

Where:

$\mathrm{m}_{3}=\left(1-\mathrm{r}_{5}-2 \mathrm{r}_{9}\right) \mathrm{A}_{\mathrm{s}}(\mathrm{NADPH})$

$\mathrm{m}_{4}=\left(\mathrm{r}_{5}+2 \mathrm{r}_{9}\right) \mathrm{A}_{\mathrm{s}}(\mathrm{NADPH})$

Rules $\mathrm{R}_{\mathrm{S}} 3, \mathrm{R}_{\mathrm{S}} 4$ and $\mathrm{R}_{\mathrm{T}} 1$ are formulated from reaction (2), (7) and (9). Rule $\mathrm{R}_{\mathrm{S}} 3$ transforms one $\mathrm{H}^{+}$ 
into $\mathrm{m}_{5} \mathrm{H}^{+}$and $\mathrm{m}_{6} \mathrm{H}^{+}$in stroma and rule $\mathrm{R}_{\mathrm{S}} 4$ transports $\mathrm{m}_{6} \mathrm{H}^{+}$from stroma into tylakoid. This is followed by rule $\mathrm{R}_{\mathrm{T}} 1$ which transports $\mathrm{m}_{6} \mathrm{H}^{+}$from tylakoid into lumen. These rules determine the concentration of $\mathrm{H}^{+}$:

$$
\begin{aligned}
& \mathrm{R}_{\mathrm{S}} 3:\left[\mathrm{H}^{+}\right]_{\mathrm{S}} \stackrel{\mathrm{r}_{1}, \mathrm{r}_{7}, \mathrm{r}_{9}}{\longrightarrow}\left[\mathrm{m}_{5} \mathrm{H}^{+}, \mathrm{m}_{6} \mathrm{H}^{+}\right]_{\mathrm{S}} \\
& \mathrm{R}_{\mathrm{S}} 4: \mathrm{m}_{6} \mathrm{H}^{+}[]_{\mathrm{T}} \stackrel{\mathrm{r}_{1}}{\longrightarrow}\left[\mathrm{m}_{6} \mathrm{H}^{+}\right]_{\mathrm{T}} \\
& \mathrm{R}_{\mathrm{S}} 1: \mathrm{m}_{6} \mathrm{H}^{+}[]_{\mathrm{L}} \stackrel{\mathrm{r}_{1}}{\longrightarrow}\left[\mathrm{m}_{6} \mathrm{H}^{+}\right]_{\mathrm{L}}
\end{aligned}
$$

Where:

$$
\mathrm{m}_{5}=\left(1-6 \mathrm{r}_{1}-4 \mathrm{r}_{7}-2 \mathrm{r}_{9}\right) \mathrm{A}_{\mathrm{s}}\left(\mathrm{H}^{+}\right)
$$

$\mathrm{m}_{6}=4 \mathrm{r}_{1} \mathrm{~A}_{\mathrm{s}}\left(\mathrm{H}^{+}\right)$

Rules $\mathrm{R}_{\mathrm{L}} 1, \mathrm{R}_{\mathrm{L}} 2$ and $\mathrm{R}_{\mathrm{T}} 2$ are formulated from reaction $\left(1,4,6\right.$ and 8). Rule $\mathrm{R}_{\mathrm{L}} 1$ transforms one $\mathrm{H}^{+}$ into $\mathrm{m}_{7} \mathrm{H}^{+}$and $\mathrm{m}_{8} \mathrm{H}^{+}$in lumen and rule $\mathrm{R}_{\mathrm{L}} 2$ transports $\mathrm{m}_{8} \mathrm{H}^{+}$into tylakoid. Subsequently rule $\mathrm{R}_{\mathrm{T}} 2$ transports $\mathrm{m}_{8} \mathrm{H}^{+}$into stroma. These rules also determine the concentration of $\mathrm{H}^{+}$:

$$
\begin{aligned}
& \mathrm{R}_{\mathrm{L}} 1:\left[\mathrm{H}^{+}\right]_{\mathrm{L}} \stackrel{\mathrm{r}_{1}, \mathrm{r}_{5}, \mathrm{r}_{6}, \mathrm{r}_{8}, \mathrm{C}_{\mathrm{L}}, \mathrm{C}_{\text {ATP }}}{\longrightarrow}\left[\mathrm{m}_{7} \mathrm{H}^{+}, \mathrm{m}_{8} \mathrm{H}^{+}\right]_{\mathrm{L}} \\
& \mathrm{R}_{\mathrm{L}} 2:\left[\mathrm{m}_{8} \mathrm{H}^{+}\right]_{\mathrm{L}} \stackrel{\mathrm{r}_{5}, \mathrm{C}_{\text {ATP }}}{\longrightarrow}\left[\mathrm{m}_{8} \mathrm{H}^{+}[]_{\mathrm{L}}\right. \\
& \mathrm{R}_{\mathrm{T}} 2:\left[\mathrm{m}_{8} \mathrm{H}^{+}\right]_{\mathrm{T}} \stackrel{\mathrm{r}_{5}, \mathrm{C}_{\text {ATP }} \longrightarrow}{\longrightarrow} \mathrm{m}_{8} \mathrm{H}^{+}[]_{\mathrm{T}}
\end{aligned}
$$

Where:

$$
\begin{aligned}
& \mathrm{m}_{7}=\left(\left(1-\mathrm{r}_{8}\right) \mathrm{A}_{\mathrm{L}}\left(\mathrm{H}^{+}\right)+\left(\mathrm{r}_{1}+\mathrm{r}_{6}\right) \mathrm{C}_{\mathrm{L}}-\mathrm{r}_{5} \mathrm{C}_{\mathrm{ATP}}\right) \\
& \mathrm{m}_{8}=\mathrm{r}_{5} \mathrm{C}_{\mathrm{ATP}}
\end{aligned}
$$

Rule $\mathrm{R}_{\mathrm{T}} 3$ transforms one PSIIh into $\mathrm{m}_{9} \mathrm{PSIIh}$ and $\mathrm{m}_{10}$ PSIIl and rule $\mathrm{R}_{\mathrm{T}} 4$ transforms one PSIIl into $\mathrm{m}_{11}$ PSIIl in tylakoid. These rules demonstrate the activity of photosystems:

$$
\begin{aligned}
& \mathrm{R}_{\mathrm{T}} 3:[\mathrm{PSIIh}]_{\mathrm{T}} \stackrel{\mathrm{r}_{\mathrm{PS}}, \mathrm{C}_{\mathrm{PS}}}{\longrightarrow}\left[\mathrm{m}_{9} \mathrm{PSIIh}_{10} \mathrm{~m}_{10} \mathrm{PSIII}_{\mathrm{T}}\right. \\
& \mathrm{R}_{\mathrm{T}} 4:[\mathrm{PSIII}]_{\mathrm{T}} \stackrel{\mathrm{C}_{\mathrm{PS}}}{\longrightarrow}\left[\mathrm{m}_{11} \mathrm{PSIII}_{\mathrm{T}}\right.
\end{aligned}
$$

Where:

$$
\begin{aligned}
& \mathrm{m}_{9}=\left(\left(1-\mathrm{r}_{\mathrm{PS}}\right) \mathrm{A}_{\mathrm{T}}(\mathrm{PSIIh})+\mathrm{C}_{\mathrm{PS}}\right), \mathrm{m}_{10}=\mathrm{r}_{\mathrm{PS}} \mathrm{A}_{\mathrm{T}}(\mathrm{PSIIh}) \\
& \mathrm{m}_{11}=\left(\mathrm{A}_{\mathrm{T}}(\mathrm{PSIIl})-\mathrm{C}_{\mathrm{PS}}\right)
\end{aligned}
$$

The rules in this system, which are either communication between compartments or transformation of objects, are non-cooperative rules executed in parallel mode. In this system, $R_{S} 1, R_{S} 2$, $\mathrm{R}_{\mathrm{S}} 3, \mathrm{R}_{\mathrm{T}} 3, \mathrm{R}_{\mathrm{T}} 4, \mathrm{R}_{\mathrm{L}} 1$ are transformation rules and $\mathrm{R}_{\mathrm{S}} 4$, $\mathrm{R}_{\mathrm{T}} 1, \mathrm{R}_{\mathrm{T}} 2, \mathrm{R}_{\mathrm{L}} 2$ are communication rules. Based on the abovementioned rules, the behavior of Photo as simulated with predetermined parameter values (constants, probabilities, strength of light and threshold) and the initial multisets. Changes of photosystems and $\mathrm{PH}$ values were examined with photosystem decreasing activity (disabled when $\mathrm{p}_{\mathrm{PS}}=0$ and enabled when $\mathrm{p}_{\mathrm{PS}}=10^{-8}$ ) and strength of light (normal light $\mathrm{v}=1000$, strong light $\mathrm{v}=10000$ and very strong light $\mathrm{v}=10^{5}$ ). Through this simulation, $\mathrm{PH}$ values and concentrations of objects were obtained after 100 iterations of rules. The results showed that photoinhibition mechanism of decreasing activity of photosystems is effective at very strong light condition $^{[6]}$.

In this model reactivity rates and constants are used by rules to determine multiplicities of various objects in the system based on specific formula. This approach is different from the common way of considering reactivity rates and constants to verify the weight of the rule in order to select which one of the rules should be executed first. Therefore in this model rules will be executed if the objects involved are present in the system. However the value of probabilities, constants, thresholds and number of objects verify the value of reactivity rate.

Modeling sodium-potassium exchange pump: Conformational transformations of the NaKpump as well as the movements of ions could be described by using the framework of membrane computing. The structure of the model will consist of three regions defined by the extracellular Environment (E), the Bilayer (B) and the intracellular Region (R). The bilayer is acting as a medium of communication between the inner intracellular region and extracellular environment. Formally the model will be written as:

$\operatorname{NaKpump}=\left(V, \mu, \omega_{E}, \omega_{B}, \omega_{R}, R_{E}, R_{B}, R_{R}\right)$

The membrane structure is not in the hierarchical structure as in the Photo model. The three compartments are positioned in the adjacent manner, in which membrane $\mathrm{B}$ mediates between $\mathrm{R}$ and $\mathrm{E}$. In this case, $\mathrm{R}$ and $\mathrm{E}$ are not linked to each other and they have links only with B. Therefore, its membrane structure can be represented as:

$\mu=\left[\left[[]_{R}\right]_{B}\right]_{E}$

The extracellular environment and the intracellular region are characterized by multisets of symbols over the alphabet:

$\mathrm{V}=\left\{\mathrm{Na}, \mathrm{KNa}, \overline{\mathrm{K}}, \mathrm{ATP}, \mathrm{ADP}, \mathrm{P}, \mathrm{E}_{1}-\mathrm{ATP}, \mathrm{E}_{2}, \mathrm{E}_{1}^{\mathrm{P}}, \mathrm{E}_{2}^{\mathrm{P}}\right\}$ 
$\mathrm{Na}, \mathrm{K}$ and $\mathrm{P}=$ Sodium, potassium and phosphate ions $\overline{\mathrm{Na}}$ and $\overline{\mathrm{K}}=$ Represents sodium and potassium ions which, at some time, are occluded within the pump inside the bilayer region

At state (h), the conformation $\mathrm{E}_{1}$ able to bind with the ATP to form $E_{1}$-ATP. The $E_{1}$-ATP, $E_{2}, E_{1}{ }^{P}, E_{2}{ }^{P}$ objects are introduced to represent the conformation states of the pump and they are characterized inside the bilayer region. The labels: $\mathrm{E}_{1}-\mathrm{ATP} \mathrm{E}_{2}$ correspond to the dephosphorylated conformations of the pump, while $\mathrm{E}_{1}^{\mathrm{P}}, \quad \mathrm{E}_{2}^{\mathrm{P}}$ correspond to the phosphorylated conformations. These elements are present only in bilayer. The initial multisets are:

$$
\begin{aligned}
& \omega_{\mathrm{R}}=\{\mathrm{nNa}, \mathrm{mK}, \mathrm{sATP}\} \\
& \omega_{\mathrm{E}}=\left\{\mathrm{n}^{\prime} \mathrm{Na}, \mathrm{m}^{\prime} \mathrm{K}\right\} \\
& \omega_{\mathrm{B}}=\phi
\end{aligned}
$$

where, $n, m, s, n^{\prime}, m^{\prime}>0$ representing object multiplicities in integers.

An evolution rule has the following generic form:

$\mathrm{R}_{\mathrm{a}}: \mathrm{C}>>\mathrm{u}[\mathrm{v}]_{\mathrm{a}} \rightarrow \mathrm{u}^{\prime}\left[\mathrm{v}^{\prime}\right]_{\mathrm{a}}$

where, $\mathrm{C}$ is condition associated to the rule and it is optional. A rule of this form is interpreted as follows: If the condition $\mathrm{C}$ is true, then multiset $\mathrm{u}$ outside membrane a and multiset $\mathrm{v}$ inside membrane a react together to produce multiset $u$ outside a and multiset $v^{\prime}$ inside a. If there is no condition then the rule is applied based on the availability of multiset $u^{\prime}$ and $v^{\prime}$ on the left hand side of the rule.

Let $A_{a}(X)$ denote the number of molecules $X$ that exist in membrane a. The sets of rules $R_{E}, R_{B}, R_{R}$, consist of the following component rules:

$\mathrm{R}_{\mathrm{R}} 1:\left(\mathrm{RA}(\mathrm{Na}) \leq \mathrm{k}_{1} \wedge \mathrm{RA}(\mathrm{K}) \geq \mathrm{k}_{2}\right)>>\mathrm{Q}$

$\mathrm{Q}=\mathrm{E}_{1}-\mathrm{ATP}[3 \mathrm{Na}]_{\mathrm{R}} \rightarrow 3 \mathrm{Na}, \mathrm{E}_{1}-\mathrm{ATP}[]_{\mathrm{R}}$

The rule $R_{R} 1$ based on steps ( $a$ and $b$ ). The rule $R_{R} 1$ will activate the pump if the following conditions will be fulfilled: $R_{A}(N A)=A_{E}(N a) / A_{R}(N a)$ is under a threshold $k_{1}$ and $R A(K)=A_{E}(K) / A_{R}(K)$ is beyond $k_{2}$, where $\mathrm{k}_{1}$ and $\mathrm{k}_{2}$ correspond to the ratios at steady-state concentrations. When three molecules of $\mathrm{N}_{\mathrm{a}}$ from the intracellular region are transported into the bilayer, the conformation state is $\mathrm{E}_{1}$-ATP:

$$
\begin{aligned}
& \mathrm{R}_{\mathrm{B}} 1:\left[3 \mathrm{Na}, \mathrm{E}_{1}-\mathrm{ATP}\right]_{\mathrm{B}} \rightarrow\left[3 \overline{\mathrm{Na}}, \mathrm{ADP}, \mathrm{E}_{1}^{\mathrm{P}}\right]_{\mathrm{B}} \\
& \mathrm{R}_{\mathrm{B}} 2:\left[\mathrm{ADP}, \mathrm{E}_{1}^{\mathrm{P}}[]_{\mathrm{R}} \rightarrow \mathrm{E}_{1}^{\mathrm{P}}[\mathrm{ADP}]_{\mathrm{R}}\right.
\end{aligned}
$$

The rules $R_{B} 1$ and $R_{B} 2$ are based on steps ( $b$ and c). Rule $R_{B} 1$ transforms $\mathrm{ATP}$ and $3 \overline{\mathrm{Na}}$ into ADP and $3 \overline{\mathrm{Na}}$ in the bilayer and the conformation $\mathrm{E}_{1}$-ATP changes into phosphorylated form $\mathrm{E}_{1}{ }^{\mathrm{P}}$. In the rule $\mathrm{R}_{\mathrm{B}} 2$, the ADP from the bilayer in phosphorylated state will move into the intracellular region. Both of these rules correspond to the autophosphorylation process of the pump:

$$
\begin{aligned}
& \mathrm{R}_{\mathrm{B}} 3:\left[3 \overline{\mathrm{Na}}, \mathrm{E}_{1}^{\mathrm{P}}\right]_{\mathrm{B}} \rightarrow\left[3 \mathrm{Na}, \mathrm{E}_{2}^{\mathrm{P}}\right]_{\mathrm{B}} \\
& \mathrm{R}_{\mathrm{B}} 4:\left[\mathrm{Na}, \mathrm{E}_{2}^{\mathrm{P}}\right]_{\mathrm{B}} \rightarrow \mathrm{Na}\left[\mathrm{E}_{2}^{\mathrm{P}}\right]_{\mathrm{B}}
\end{aligned}
$$

The rules $R_{B} 3$ and $R_{B} 4$ are based on steps (c-d). Rule $\mathrm{R}_{\mathrm{B}} 3$ changes the conformation $\mathrm{E}_{1}{ }^{\mathrm{P}}-\mathrm{E}_{2}{ }^{\mathrm{P}}$ and deocclude $3 \overline{\mathrm{Na}}$ into $3 \overline{\mathrm{Na}}$. This changes trigger rule $\mathrm{R}_{\mathrm{B}} 4$, where one $\mathrm{Na}$ is immediately released into the environment:

$$
\mathrm{R}_{\mathrm{B}} 5:\left[2 \mathrm{Na}, \mathrm{E}_{2}^{\mathrm{P}}\right]_{\mathrm{B}} \rightarrow 2 \mathrm{Na}\left[\mathrm{E}_{2}^{\mathrm{P}}\right]_{\mathrm{B}}
$$

The rule $R_{B} 5$ is based on step (e). Rule $R_{B} 5$ releases $2 \mathrm{NA}$ into environment when the bilayer is in the conformation state of $\mathrm{E}_{2}{ }^{\mathrm{P}}$ :

$\mathrm{R}_{\mathrm{E}} 10: 2 \mathrm{~K}\left[\mathrm{E}_{2}^{\mathrm{P}}\right]_{\mathrm{B}} \rightarrow\left[2 \mathrm{~K}, \mathrm{E}_{2}^{\mathrm{P}}\right]_{\mathrm{B}}$

The rule $R_{E} 10$ is based on step (f). Rule $R_{E} 10$ transports $2 \mathrm{~K}$ from environment into the bilayer when the conformation state is $\mathrm{E}_{2}{ }^{\mathrm{P}}$ :

$\mathrm{R}_{\mathrm{B}} 6:\left[2 \mathrm{~K}, \mathrm{E}_{2}^{\mathrm{P}}\right]_{\mathrm{B}} \rightarrow\left[2 \overline{\mathrm{K}}, \mathrm{E}_{2}, \mathrm{P}\right]_{\mathrm{B}}$

$\mathrm{R}_{\mathrm{B}} 7: \mathrm{E}_{2} \mathrm{P}[]_{\mathrm{R}} \rightarrow \mathrm{E}_{2}[\mathrm{P}]_{\mathrm{R}}$

The rules $R_{B} 6$ and $R_{B} 7$ are based on steps ( $f$ and $g$ ). Rule $\mathrm{R}_{\mathrm{B}} 6$ occludes $2 \mathrm{~K}$ into $2 \overline{\mathrm{K}}$ and transforms $\mathrm{E}_{2}{ }^{\mathrm{P}}$ into $E_{2}$. Rule $R_{B} R$ produces $P$ in bilayer which is then transported into the intracellular region.

$$
\begin{aligned}
& \mathrm{R}_{\mathrm{R}} 2: \mathrm{E}_{2}[\mathrm{ATP}]_{\mathrm{R}} \rightarrow \mathrm{E}_{2}, \mathrm{ATP}[]_{\mathrm{R}} \\
& \mathrm{R}_{\mathrm{B}} 8:\left[2 \overline{\mathrm{K}}, \mathrm{E}_{2}, \mathrm{ATP}\right]_{\mathrm{B}} \rightarrow\left[2 \mathrm{~K}, \mathrm{E}_{1}, \mathrm{ATP}\right]_{\mathrm{B}}
\end{aligned}
$$

The rules $R_{R} 2$ and $R_{B} 8$ are based on steps ( $g$ and h). Rule $R_{R} 2$ releases ATP from the intracellular region intobilayer when the conformation state is $\mathrm{E}_{2}$. The next rule, $\mathrm{R}_{\mathrm{B}} 2$, de-occludes $2 \overline{\mathrm{K}}$ with $\mathrm{ATP}$ to produce $2 \mathrm{~K}$ and transforms the conformation state $E_{2}$ into $E_{1}$-ATP: 
$\mathrm{R}_{\mathrm{B}} 9: 2 \mathrm{~K}, \mathrm{E}_{1}, \mathrm{ATP}[]_{\mathrm{R}} \rightarrow \mathrm{E}_{1}-\mathrm{ATP}[2 \mathrm{~K}]_{\mathrm{R}}$

The rule $R_{B} 2$ is based on steps (a-h). Rule $R_{B} 9$ releases $2 \mathrm{~K}$ from bilayer into intracellular region when the conformation state is $\mathrm{E}_{1}$-ATP.

The conformation states are represented as objects in the bilayer and they operate in two ways. Firstly, they act as catalysts to stimulate a transformation process or a transportation or release of an object to an adjacent compartment. Secondly, they are also able to transform from one to another conformation states.

The transformation rules occur only inside of the bilayer. The rules are $R_{B} 1, R_{B} 3, R_{B} 6$ and $R_{B} 8$. The communication rules are between the intracellular region and bilayer and, between bilayer and environment. The rules are $R_{R} 1, R_{R} 2, R_{B} 1, R_{B} 2, R_{B} 4$, $\mathrm{R}_{\mathrm{B}} 5, \mathrm{R}_{\mathrm{B}} 7, \mathrm{R}_{\mathrm{B}} 9$ and $\mathrm{R}_{\mathrm{E}} 10$.

In NaKpump the rules are executed in a maximal parallel and nondeterministic manner. The real number defining multiplicity factors, occurring in Photo, are replaced by integers defining number of molecules. In this model there are no additional functions computing the associated multiplicity values. These values are constant elements in the rules defining the system behavior. A new factor occurring in this model is the existence of a (Boolean) condition associated with rule that need to be fulfilled for this rule to be applied (rule $R_{R} 1$ ). This model is also not utilizing reactivity rates or constants as in the Photo model. This is because NaKpump is under the control of regulatory mechanisms. For instance, the intracellular concentrations of ions determine the maximal activity of the pump in which whenever $\mathrm{Na}$ ions rises, the pump works more rapidly to expel the excess of $\mathrm{N}_{\mathrm{a}}$ ions, thus lowering its concentration to a steady state value. In addition to that, the rate constants of competing steps that would decrease the efficiency are quite small and this ensures that the binding and the release of substrate occur at the proper point in the cycle of the pump ${ }^{[4]}$.

\section{DISCUSSION}

The two examples discussed above showed that, there are fundamental principles in representing biological processes using membrane computing although there are differences in specific approaches in representing and implementing the models. The main components of abovementioned models are objects, multisets, membrane structure, compartments and rules.

Membrane structure: Membrane structures as shown in these biological processes are either in hierarchical compartments or the compartments are positioned at the same level. The Photo is represented as three compartments in hierarchical manner and NaKpump is represented as three compartments at the same level. It would be easier to specify the links for membrane structure of a hierarchical system, since in this structure a compartment is required to communicate with its adjacent compartments based on the hierarchical arrangements.

Meanwhile in NaKpump, the membrane structure is formulated by taking the links between the adjacent compartments, in which in this case there is no possible link between $\mathrm{R}$ and $\mathrm{E}$, and, $\mathrm{B}$ is mediating between them. R, E and B are arranged in a sequence in NaKpump. The links in this membrane structure could be formed because there is only a single adjacent compartment for each compartment and the positions of the compartments in the system are fixed according to a sequence. However if there is more than one adjacent compartment to a specific compartment and there is no sequence to position the compartments, links have to be established and in this case binding rules are needed ${ }^{[7]}$. Membrane structure for most of the biological system is quite complex and this could be represented as tissue or population type of membrane computing $^{[7]}$.

Objects and multisets: As can be seen in the both biological processes, besides chemical substances, molecules and ions, there are also other elements with specific characteristics participating in biological processes. These elements as well need to be regarded as objects to model the processes. In Photo, PSI and PSII, pigments that are exited by light, are also formalized as objects. In NaKpump the conformations states $\mathrm{E}_{1}-\mathrm{ATP}, \mathrm{E}_{2}, \mathrm{E}_{1}^{\mathrm{P}}, \mathrm{E}_{2}^{\mathrm{P}}$ represent specific characteristics of bilayer. These states act as stimulus to alter the character of the ion inside the compartment. In that case, in order to model the processes, conformations states are also considered as objects. In this respect, there are mixture of different characters of objects in Photo and NaKpump. On the other hand, it is also essential to determine the way to represent and measure the amount of objects in the system. The objects concentrations are measured in real numbers in Photo and, in integers in NaKpump. The real number multiplicities of objects in Photo are determined by specific formulas that are represented in the rules. The integer multiplicities of objects in NaKpump are generated based on the interactions of objects in the rules.

Rules and parameters: The rules explained in both biological processes, are extracted directly or indirectly 
from the reactions taking place in real biological processes. In Photo the rules are formulated by taking into account the related reactions in photosynthesis, whereas in NaKpump the reactions themselves are used as rules. All the rules explained above are communication and transformation rules. In both cases, the reactants on the left hand side of the rule are evolving into products on the right hand side of the rule. These rules could also contain reactivity rate and condition. In Photo rules, reactivity rates and constants are used to determine the real number multiplicities of objects. In this case, all rules have the same possibilities to be executed at certain time step if the reactants in the rules are present. This means that, the various reactivity rates and constants are used to accumulate and control the multiplicities of objects in Photo. On the other hand, the rules in NaKpump are without any reactivity rates. This means that all rules are possible to be executed if the reactants are present. However, the system is operating in a cycle in which the products that are generated by a rule are used as reactants by the following rule. The Boolean condition is another attribute that could be present in the rule. In NaKpump, the Boolean condition is generated by measuring the ratios of ion $\mathrm{Na}$ and ion $\mathrm{K}$ in the system. True Boolean condition in rule $R_{R} 1$ is indicating the starting point of the cycle of the process, and, when the Boolean condition is False the process will not start. Therefore, Boolean condition can act as decider in executing a rule. All rules defined in both examples above are communication and transformation rules. But this won't be the case for complex biological processes which could involve the structural change of membrane. Some of the common biological reactions that alter the membrane structure are membrane division, membrane dissolving, membrane differentiation, membrane death, exocytosis and endocytosis. In division rule a compartment will be divided into two new compartments where both of them are of same type as the original compartment but the contents (objects or multisets) of the original compartment will be divided among them based on conditions determined by the rule. In dissolving rule a compartment will be dissolved and its contents will be moved into the adjacent compartment outside it. In differentiation rule a compartment type will be converted into another type. This means that the content and rules of new compartment will emulate the character of the new type assigned to it. If a death rule applied on the compartment, then it will be deleted from the system along with its contents. In exocytosis rule a compartment enclosed inside another compartment will be moved out from the latter, and the contents and rules of the former will remain intact. In endocytosis rule a compartment outside another compartment will be moved inside the latter, and the contents and rules of the former will remain intact. All these reactions involve structural changes that need readjustment with the links between compartments as well as in the hierarchical structure of the system. In that respect, the membrane computing formalism needs expansion in order to accommodate these reactions.

Simulation strategies: In Photo, the value of parameters and reactivity rates are based on specific formulas. These elements determine the concentration of objects in the system. Some reactivity rates are fixed and some are determined according to certain conditions $^{[1]}$. However, the simulation strategy used is based on the selection of these reactivity factors which determine the direction of the simulation. In this way, the model is executed in maximally parallel but the rule selection is determined based on the reactivity rates. However, the simulation implemented here is not based on stochastic algorithm such as Gillespie Algorithm ${ }^{[10]}$ to simulate probabilistic model. Since the alterations of reactivity rates in this model are based on specific conditions and are not based on the concentration of objects in the system, it will be difficult to use the Gillespie Algorithm. Meanwhile, NaKpump is a cycle and only a rule will be executed at a time when the required objects to be consumed by the rule is available. Therefore the maximally parallel and nondeterministic character of membrane computing is not practically implemented.

\section{CONCLUSION}

The examples above showed that the biological processes could be modeled in better way by using membrane computing. This approach can counter some of the limitations in the conventional method based on differential equations. This is mainly because membrane computing is capable of abstracting those biological structure and processes to represent them in a formal way without disregarding its biological characteristics.

The examples also demonstrate the modeling capabilities of membrane systems, to the aim of description of specific cellular phenomena. The biological data (available from laboratory experiments) concerning a particular biological processes, allow to define model using membrane computing which have turned out to be extendible in describing some more distinct natural conditions, besides those analyzed in laboratories by microbiologists. Therefore, it is thus 
possible to infer that a preliminary but rather powerful modeling potentiality of membrane computing has been established.

Though the membrane computing formalism is able to represent most of the biological processes that involve membrane structure and fundamental processes, it will need to expand its formalism to represent more complex biological processes that involve hierarchical structure as well as structural change of membrane.

\section{REFERENCES}

1. Nishida, T.Y., 2002. Simulations of photosynthesis by a K-subset transforming system with membranes. Fundam. Inform., 49: 249-259. http://portal.acm.org/citation.cfm?id=634884

2. Besozzi, D., 2003. Computational and modeling power of P systems. Ph.D. Thesis, Faculty of Science Mathematics, University Degli Studi Di Milano, Italy.

http://bmc.hust.edu.cn/psystems/download\%5CBes ozziPhdThesis.pdf

3. Ardelean, I.I., D. Besozzi, M.H. Garzon, G. Mauri and S. Roy, 2005. P-System Models for Mechanosensitive Channels. Springer Verlag, Berlin, ISBN: 978-3-540-25017-3, pp: 43-81.

4. Besozzi, D. and G. Ciobanu, 2004. A P-system description of the sodium-potassium pump. Lecture Notes Comput. Sci., 3365: 210-223. DOI: 10.1007/b106721

5. Romero-Campero, F.J. and M.J. Pérez-Jiménez, 2008. A Model of the quorum sensing system in vibrio fischeri using P systems. Artif. Life, 14: 95-109. DOI:10.1162/artl.2008.14.1.95

6. Paun, G., 2002. Membrane Computing: An Introduction. Springer-Verlag, Berlin, ISBN: 3540436014, pp: 419.

7. Bernardini, F. M. Gheorghe, N. Krasnogor, R.C. Muniyandil and M.J. Perez-Jimenez et al., 2006. On P systems as a modeling tool for biological systems. Lecture Notes Comput. Sci., 3850: 114-133.

http://cat.inist.fr/?aModele $=$ afficheN\&cpsidt $=1918$ 3831
8. Perez-Jimenez, M.J. and F.J. Romero-Campero, 2006. P systems, a new computational modeling tool for systems biology. Lecture Notes Comput. Sci., 4220: 176-197. DOI: 10.1007/11880646

9. Ciobanu, G., G. Paun and M.J. Perez-Jimenez, 2006. Application of Membrane Computing. 1st Edn., Springer, Berlin, ISBN: 9783540299370, pp: 439.

10. Gillespie, D.T., 2001. Approximate accelerated stochastic simulation of chemically reacting systems. J. Chem. Phys., 115: 1716-1733. http://direct.bl.uk/bld/PlaceOrder.do?UIN=099423 $328 \& \mathrm{ETOC}=\mathrm{RN} \&$ from $=$ searchengine 